Bul. Agrohorti 3 (2) : $252-262$ (2015)

\title{
Pengelolaan Pembibitan Karet (Hevea brassiliensis Muel Arg.) di Balai Penelitian Sembawa, Palembang, Sumatera Selatan
}

\author{
Manajement Of Rubber Nursery (Hevea brassiliensis Muel Arg.) at Rubber Research Sembawa in \\ Palembang, South Sumatera \\ Putri Ratna Sari dan Supijatno*
}

\author{
Agronomi dan Hortikultura, Fakultas Pertanian, Institut Pertanian Bogor \\ (Bogor Agricultural University), Jl. Meranti, Kampus IPB Darmaga, Bogor 16680, Indonesia \\ Telp.\&Faks.62-251-8629353 e-mail agronipb@indo.net.id \\ *Penulis untuk korespondensi: supijatno@yahoo.com \\ Disetujui 7 Mei 2015 / Published online 15 Mei 2015
}

\begin{abstract}
This research undertaken to determine the rubber nursery management. This research carried out at the Rubber Research Sembawa, Pelembang, South Sumatra from February to June 2014. Urusan Bahan Tanam (UBT) which provide rubber seedlings move from the plantation and has its own organizational structure with the aim of focusing on the provision of seeds required by consumers. Demand for rubber seedlings are very much of all the public, private, government, and farmers resulted in the UBT should have good management in meeting consumer demand. The lack of the amount of land required to grow rootstock is the main factor that led to the UBT overwhelmed in order to meet the rubber seeds needed by consumers. The process of purchasing rubber seedlings UBT performed directly in the office where the consumer must first pay a down payment of $30 \%$ and a certification activities conducted by the Board of Certification and Crops Plantation.
\end{abstract}

Keywords: Rubber seedling, grafting, manajement, UBT

\begin{abstract}
ABSTRAK
Penelitian ini dilakukan untuk mengetahui pengelolaan pembibitan karet. Penelitian dilakukan di Balai Penelitian Sembawa, Pelembang, Sumatera Selatan pada bulan Februari sampai Juni 2014. Bagian Urusan Bahan Tanam (UBT) telah memisahkan diri dari bagian kebun dan memiliki susunan organisasi sendiri dengan tujuan berfokus pada penyediaan bibit yang dibutuhkan oleh konsumen. Permintaan bibit karet yang sangat tinggi dari kalangan masyarakat baik swasta, pemerintah, dan petani mengakibatkan UBT harus memiliki manajemen yang baik dalam memenuhi permintaan konsumen. Terbatasnya jumlah lahan yang diperlukan untuk menanam batang bawah merupakan faktor utama yang menyebabkan UBT tidak dapat dalam memenuhi seluruh permintaan bibit karet yang dibutuhkan oleh konsumen. Proses pembelian bibit karet dilakukan langsung di kantor UBT, konsumen terlebih dahulu membayar uang muka sebesar $30 \%$ dan kegiatan sertifikasi dilakukan oleh Badan Sertifikasi dan Tanaman Perkebunan.
\end{abstract}

Kata kunci: bibit karet, okulasi, pengelolaan, UBT 


\section{PENDAHULUAN}

Tanaman karet (Hevea brasiliensis Muell Arg.) merupakan tanaman perkebunan yang memiiki nilai ekonomi sangat tinggi terutama bagi Indonesia yang merupakan negara penghasil karet alam terbesar kedua di dunia setelah Thailand. Hasil berupa getah atau lateks dari tanaman ini dimanfaatkan sebagai sumber bahan utama industri, mulai dari peralatan masak, alat medis, transportasi dan lain-lain. Perkembangan teknologi dan industri yang semakin berkembang menyebabkan penggunaan karet alam semakin luas dalam kehidupan sehari-hari dan mendorong peningkatan konsumsi karet dunia serta permintaan karet alam. Sebagai salah satu negara pengekspor karet alam terbesar dunia, Indonesia memiliki peluang besar dalam peningkatan hasil produktivitas tanaman karet ini.

Kontribusi yang dikenal juga sebagai "green factory" ini dalam meningkatan devisa negara sudah sangat signifikan. Peningkatan produktivitas perkebunan karet Indonesia sejak tahun 1963 hingga sekarang sudah mulai membaik, hal ini diakibatkan dari adanya perhatian pemerintah terhadap peremajaan tanaman karet dengan menggunakan klon-klon unggul anjuran dan perbaikan ekonomi petani karet. Upaya peningkatan kualitas dan kuantitas karet yang optimal, juga harus ditunjang oleh ketersediaan bibit yang berkualitas dari klon-klon unggul (Chatib, 2007).

Ekspor karet Indonesia selama 20 tahun terakhir terus menunjukkan adanya peningkatan dari 1.0 juta ton pada tahun 1985 menjadi 1.3 juta ton pada tahun 1995 dan pada tahun 2007 menjadi 2.75 juta ton. Pendapatan non-migas ini pada tahun 2007 mencapai US\$ 6.65 milyar, 5\% dari pendapatan non-migas (Bank Indonesia, 2007) dan tahun 2010 ekspor karet Indonesia mengalami peningkatan sebesar $10 \%$. Data perbandingan antara luas lahan karet, produksi dan produktivitas karet tahun 20072011 dapat dilihat pada Tabel 1.

Tabel 1. Perbandingan luas lahan produksi, dan produktivitas karet tahun 2007 - 2011

\begin{tabular}{cccc}
\hline Tahun & $\begin{array}{c}\text { Luas Lahan } \\
(\text { juta Ha) }\end{array}$ & $\begin{array}{c}\text { Produksi } \\
\text { (juta ton) }\end{array}$ & $\begin{array}{c}\text { Pruduktivitas } \\
(\text { Kg/Ha) }\end{array}$ \\
\hline 2007 & 3.41 & 2.75 & 967 \\
2008 & 3.42 & 2.75 & 994 \\
2009 & 344 & 2.44 & 901 \\
2010 & 3.45 & 2.74 & 986 \\
2011 & 3.46 & 2.99 & 1071 \\
2012 & 3.48 & 3.04 & 1080 \\
\hline
\end{tabular}

Sumber : vibiznews.com

Peningkatan kontribusi karet alam Indonesia dalam meningkatkan devisa negara ini tidak diimbangi dengan penerapan budidaya yang baik terlihat pada masih rendahnya produktivitas karet Indonesia. Masalah yang paling pokok adalah penggunaan bahan tanam, penggunaan benih unggul bermutu untuk komoditi karet yang masih sangat rendah sekitar 41\% (Disbun Sumut, 2012). Tanaman karet umumnya diperbanyak melalui okulasi, sehingga untuk menghasilkan bibit yang baik perlu mempersiapkan adanya batang atas dan batang bawah. Batang bawah berupa tanaman semaian dan biji klon anjuran sedangkan batang atasnya berasal dari mata klon-klon anjuran (Haryanto, 2012).

Penggunaan benih unggul dan bermutu untuk komoditas karet terutama pada perkebunan karet merupakan kendala yang harus diperhatikan dalam meningkatkan produktivitas karet Indonesia. Pemulia dan balai-balai penelitian karet tidak banyak yang dapat menyediakan bibit unggul dan bermutu karena keterbatasan sumber entres, scion dan kemurnian bibit tersebut. Para pengusaha karet pun banyak yang mengeluhkan tentang ketersediaan bibit karet yang unggul dan bermutu serta banyak sekali pemalsuan terhadap bibit karet hasil okulasi. Prospek bisnis penyediaan bibit karet menjadi usaha yang sangat menjanjikan karena pasar yang masih terbuka dan potensi keuntungan yang akan didapatkan oleh penangkar bibit sangat besar. Tujuan penelitian ini untuk mengetahui dan menganalisis pengelolaan pembibitan karet di Balai Penelitian Sembawa, Palembang, Sumatera Selatan.

\section{BAHAN DAN METODE}

Penelitian ini dilaksanakan di Perkebunan Balai Penelitian Sembawa lokasi kebun Sembawa, Palembang Sumatera Selatan. Penelitian 
berlangsung selama empat bulan yaitu Februari hingga Juni 2014. Metode yang digunakan pada penelitian ini yaitu metode langsung dan metode tidak langsung. Metode langsung dilakukan dengan mengikuti seluruh aspek teknik yang ada di lapangan sedangkan metode tidak langsung dilaksanakan dengan pengambilan data melalui arsip-arsip ataupun laporan-laporan yang ada di perusahaan dengan jangka waktu tiga sampai lima tahun terakhir. Kedua metode ini dilakukan untuk mengumpulkan data primer dan data sekunder yang dibutuhkan selama penelitian.

Kegiatan teknis dimulai dari divisi Urusan Bahan Tanam hingga Divisi III karet. Kegiatan manejerial diamati mulai dari pendamping mandor kerja, mandor besar, krani kantor, krani timbang, hingga pendamping asisten dalam melaksanakan fungsi pengawasan, pengecekan buku harian, mencatat hasil produksi dan lain-lain.

\section{Pengamatan dan Pengumpulan Data}

Pengumpulan data yang dilakukan dalam kegiatan magang ini menggunakan data primer dan data sekunder. Data primer merupakan data yang diamati langsung melalui pengamatan dan wawancara dengan pekerja di lapangan yang meliputi:

Kapasitas dan Tingkat Keberhasilan Okulasi. Mengetahui kapasitas okulasi yang dapat dilakukan oleh pekerja dan persentase keberhasilan dari okulasi yang dilakukan.

Tinggi Bibit $(\mathrm{cm})$. Pengukuran tinggi dilakukan pada bibit hasil okulasi diukur dari pertautan okulasi. Pengamatan ini menggunakan tanaman contoh dengan cara mengambil 1 - 2\% dari jumlah tanaman yang ada di lapangan dengan penyebaran variasi umur dan dilakukan sebulan sekali.

Diameter Bibit Okulasi (cm). Diameter bibit diukur $5 \mathrm{~cm}$ dari pertautan okulasi dengan menggukan jangka sorong atau meteran. Pengamatan ini menggunakan tanaman contoh dengan cara mengambil 1 - $2 \%$ dari jumlah tanaman yang ada di lapangan dengan penyebaran variasi umur dan dilakukan sebulan sekali.

Jumlah Payung. Payung pada karet merupakan serangkaian daun yang telah membuka sempurna pada tanaman karet. Pengamatan ini menggunakan tanaman contoh dengan cara mengambil $1-2 \%$ dari jumlah bibit yang ada di lapangan dengan penyebaran variasi umur dan dilakukan sebulan sekali.
Sumber Entres dan Scion. Mengetahui klon entres dan rootstock yang digunakan, luas kebun, jumlah tanaman, proses sertifikasi yang dilakukan oleh perusahaan.

Transportasi Bibit. Mengetahui dan menganalisis kapasitas produksi bibit, pengangkutan, jaminan mutu, sistem pembayaran yang dilakukan, tujuan pengiriman, serta frekuensi pengangkutan bibit dari perusahaan.

Data sekunder merupakan data dan informasi yang dikumpulkan dari arsip-arsip perusahaan. Data sekunder ini meliputi:

Kondisi Umum Kebun. Kondisi ini meliputi tanah dan agroklimat. Informasi ini didapatkan dari data-data yang ada di perusahaan.

Produksi Bibit. Kemampuan perusahaan atau kebun untuk memproduksi bibit dalam jangka waktu lima tahun terakhir. Informasi ini didapatkan dari laporan data produksi yang ada di perusahaan.

Pemasaran. Mengetahui distribusi, klon bibit yang diperjualbelikan, cara pembelian, dan tujuan pengguna dari bibit dari bibit karet selama tiga atau lima tahun terakhir.

Organisasi dan Tenaga Kerja. Mengetahui susunan organisasi dan jumlah tenaga kerja yang terdapat pada bagian-bagian pengelolaan bibit karet dan spesifikasi tenaga kerja yang dibutuhkan dalam setiap pengelolaan.

\section{KONDISI UMUM}

Kondisi iklim di Kebun Riset Balai Penelitian Sembawa menurut klasifikasi Schmidth dan Ferguson memiliki tipe iklim B (basah) dengan nilai $Q$ yaitu 30.3 dengan perbandingan antara bulan kering (bulan dengan curah hujan $<60 \mathrm{~mm}$ ) dan bulan basah (bulan dengan curah hujan $>100 \mathrm{~mm}$ ) sama dengan nol atau Q dibawah 14.3-33.3\%. Kelembaban udara rata-rata berkisar antara $80-90 \%$ dan suhu udara maksimum setiap tahun $32{ }^{\circ} \mathrm{C}$ serta suhu udara minimum $22{ }^{\circ} \mathrm{C}$. Curah hujan rata-rata 2 $200 \mathrm{~mm} \mathrm{tahun}^{-1}$ serta terdapat dua bulan kering, yaitu bulan Juli dan Agustus. Jenis tanah podsolik merah kuning dengan tekstur lempung berliat hingga berpasir, drainase agak baik, dan struktur teguh. Ketinggian tempat $\pm 10 \mathrm{~m}$ diatas permukaan laut dan topografi tergolong datar sampai berombak dengan lereng $0-15 \%$. Kesuburan tanah tergolong rendah sampai sedang.

Luas Areal Konservasi dan Tata Guna Lahan

Perkebunan Karet Balai Penelitian Sembawa lokasi Kebun Riset Sembawa memiliki luas lahan 
Bul. Agrohorti 3 (2) : $252-262$ (2015)

mencapai 3314.23 ha. Luas kebun riset karet TM dan TBM (Div I, II, III) adalah 1399.43 ha. Penggunaan lahan di Balai Penelitian Sembawa lokasi kebun riset Sembawa dapat dilihat pada Tabel 2.

Tabel 2. Rincian luasan areal Balai Penelitian Sembawa, lokasi Kebun Riset Sembawa

\begin{tabular}{|c|c|c|c|c|c|c|c|c|c|}
\hline \multirow{2}{*}{ No } & \multirow{2}{*}{ Uraian } & \multicolumn{7}{|c|}{ Luas Areal Divisi(ha) } & \multirow{2}{*}{ Jumlah } \\
\hline & & Pembibitan & I & II & III & IV & V & Pabrik & \\
\hline 1 & Tm Karet & & 305.81 & 270.04 & 386.67 & & & & 962.5 \\
\hline 2 & TBM karet & & 126.73 & 310.18 & 0 & & & & 436.9 \\
\hline 3 & Pembibitan & & 28.63 & 59.37 & & & & & 88.0 \\
\hline 4 & Kebun entres & & 20.8 & & & & & & 20.8 \\
\hline 5 & Jalan dalam areal kebun & & 18.27 & 19.20 & 11.50 & 23.00 & 16.640 & & 88.6 \\
\hline 6 & Area lainnya & & 3.04 & 77.58 & 82.53 & 29.68 & 327.70 & & 520.5 \\
\hline 7 & TBM sawit & & & & & 5.00 & 45.00 & & 50.0 \\
\hline 8 & TM sawit & & 31.00 & 18.49 & 39.48 & 536.15 & 548.70 & & 1200.8 \\
\hline 9 & Emplasmen & & 30.54 & & & & & & 30.5 \\
\hline & Total & & 515.39 & 695.49 & 520.18 & 593.83 & 938.04 & 3.5 & 3314.2 \\
\hline
\end{tabular}

Sumber : Laporan tata guna lahan kebun Balai Penelitian Sembawa, lokasi Kebun Riset Sembawa

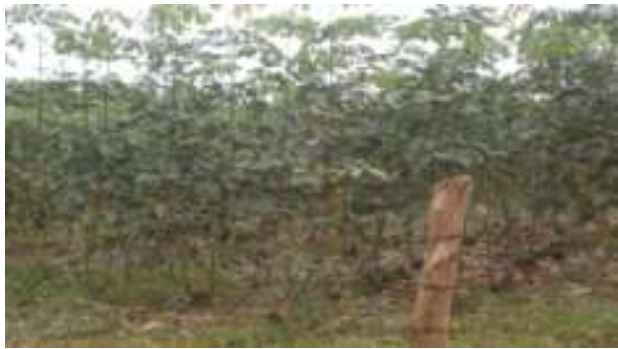

(a)

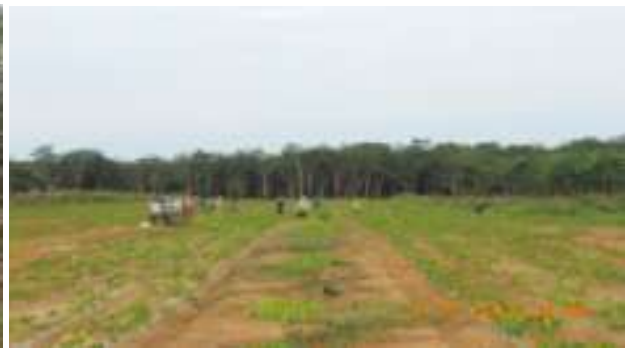

(b)

Gambar 1. Kondisi kebun : (a) kebun entres; (b) kebun batang bawah

\section{Keadaan Tanaman dan Produksi}

Kebun Balai Penelitian Sembawa mulai melakukan pembukaan lahan dan penanaman pada tahun 1982 hingga sekarang. Jarak tanam yang digunakan bervariasi karena berfokus pada penelitian tanaman karet seperti $7 \mathrm{~m} \times 3 \mathrm{~m}, 6 \mathrm{~m} \times 3$ $\mathrm{m}$, dan ukuran jarak tanam lainnya. Klon klon tanaman yang digunakan merupakan klon mixed, dimana dalam satu lokasi terdapat bermacam- macam jenis klon karet yang unggul dan anjuran. Tahun tanam karet TM terdiri dari tahun tanam 1982, 1983, 1984, 1985, 1987, 1988, 1992, 1995, 1995, 1997, 1999, 2000, 2001, 2003, 2004, 2005, 2006, 2008, sedangkan untuk TBM karet tahun tanam 2009, 2010, 2011, 2012, 2013 yang tersebar di setiap divisi karet. Produksi dan produktivitas lateks tahun 2004 - 2014 dapat dilihat pada Tabel 3 untuk kebun riset yang berlokasi di Sembawa. 
Bul. Agrohorti 3 (2) : $252-262$ (2015)

Tabel 3. Produksi dan produktivitas lateks di Balai Penelitian Sembawa tahun 2004 - 2013

\begin{tabular}{cccr}
\hline Tahun & Luas (ha) & Produksi $(\mathrm{kg})$ & Produktivitas $(\mathrm{kg})$ \\
\hline 2004 & 1172.15 & 1588338 & 1355.06 \\
2005 & 1084.02 & 1272993 & 1174.33 \\
2006 & 1085.32 & 1292397 & 1190.80 \\
2007 & 1116.68 & 1341486 & 1201.32 \\
2008 & 1125.71 & 1487789 & 1321.65 \\
2009 & 1133.16 & 1497882 & 1321.86 \\
2010 & 1156.34 & 1539068 & 1330.98 \\
2011 & 996.45 & 1598831 & 1604.53 \\
2012 & 938.57 & 1492826 & 1590.53 \\
2013 & 923.60 & 1532649 & 1659.43 \\
\hline
\end{tabular}

Sumber : Kantor Balai Penelitian Sumbawa

Kebun karet Balai Penelitian Sembawa merupakan kebun yang di gunakan untuk penelitian sehingga produktivitas $\mathrm{ha}^{-1}$ lateksnya, tidak seperti perusahaan swasta lainnya yang berfokus pada

Tabel 4. Tabel produksi SMT bertahun tanam

\begin{tabular}{|c|c|c|c|c|c|}
\hline \multirow[t]{2}{*}{ Tahun Tanam } & \multicolumn{5}{|c|}{ Produksi tahun $^{-1}$ (batang) } \\
\hline & 2009 & 2010 & 2011 & 2012 & 2013 \\
\hline 2006 & 0 & & & & \\
\hline 2007 & 549304 & 0 & & & \\
\hline 2008 & 491187 & 16497 & & & \\
\hline 2009 & 271813 & 397474 & 0 & & \\
\hline 2010 & & 562256 & 408646 & 0 & \\
\hline 2011 & & & 360533 & 467544 & 0 \\
\hline 2012 & & & & 858592 & 543000 \\
\hline 2013 & & & & & 1033373 \\
\hline Jumlah & 1312304 & 966225 & 769179 & 1326136 & 1576373 \\
\hline
\end{tabular}

Sumber : Laporan manajemen urusan bagian tanam (UBT)

\section{Struktur Organisasi dan Ketenagakerjaan}

Perkebunan Balai Penelitian Sembawa lokasi dipimpin oleh Kepala Kebun dan Divisi Urusan Bahan Tanam yang memisahkan diri dari bagian kebun dipimpin oleh Kepala UBT yang membawahi tingginya hasil produksi lateks. Produksi bibit Stump Mata Tidur (SMT) dihasilkan tahun 2009 2013 dapat dilihat pada Tabel 4.

Tabel 5. Jumlah dan komposisi tenaga kerja urusan bahan tanam (UBT)

\begin{tabular}{lc}
\hline Jabatan & TK UBT ( orang) \\
\hline Karyawan Staff & 2 \\
Bulanan Tetap & 16 \\
Harian Lepas/musiman & 263 \\
Karyawan Tidak Tetap : \\
Borongan
\end{tabular}

2 asisten. Tenaga kerja yang terdapat baik pada Kebun maupun UBT terdiri dari staf, karyawan, buruh tetap, buruh lepas, dan pekerja musiman. Komposisi tenaga kerja pada UBT dapat dilihat pada Tabel 5.

Sumber : Laporan ketenagakerjaan UBT 


\section{HASIL DAN PEMBAHASAN}

Tabel 6. Kapasitas dan persen keberhasilan okulasi

\begin{tabular}{llccc}
\hline no & Nama Okulator & $\begin{array}{c}\text { jumlah batang yang } \\
\text { diokulasi (plastik) }\end{array}$ & Keberhasilan Okulasi (batang) & Tingkat keberhasilan (\%) \\
\hline 1 & Ardyanto & 300 & 211 & 70.3 \\
2 & Mirawati & 300 & 204 & 68.0 \\
3 & Priani & 230 & 214 & 71.3 \\
4 & Rumawati & 290 & 172 & 57.3 \\
5 & Fitri S & 350 & 250 & 83.3 \\
6 & Turiman & 300 & 207 & 69.0 \\
7 & Nunung & 300 & 200 & 66.6 \\
8 & Supriatin & 230 & 230 & 76.6 \\
9 & Johan limau & 300 & 235 & 78.3 \\
10 & Andre Alfiansyah & 400 & 260 & 86.6 \\
11 & Ponirah & 300 & 200 & 66.6 \\
12 & Boyem & 300 & 206 & 68.6 \\
13 & Suparmi & 300 & 180 & 60.0 \\
14 & Surjiman & 310 & 250 & 83.3 \\
15 & Boitu Akbar & 300 & 220 & 73.3 \\
\hline & Jumlah & 4510 & 3239 & 1079.6 \\
\hline
\end{tabular}

Berdasarkan hasil pengamatan tingkat keberhasilan okulasi, okulator atau orang yang melakukan kegiatan okulasi rata-rata dapat mengokulasi sesuai dengan target, akan tetapi tingkat keberhasilan tidak mencapai $80 \%$ atau sekitar 240 batang. Okulasi yang umumnya dilakukan di Balai Penelitian Sembawa adalah okulasi coklat. Kegiatan okulasi dilakukan dengan cara borongan, dimana norma yang diberlakukan untuk setiap okulator yaitu bisa mengokulasi sebanyak-banyaknya minimal 300 bungkus okulasi atau 300 batang per hari dengan tingkat keberhasilan sebesar $80 \%$.

Faktor yang menyebabkan rendahnya tingkat keberhasilan okulasi dikarenakan jauhnya lokasi lahan batang bawah yang diokulasi dengan lokasi lahan batang entres sehingga kualitas mata entres yang digunakan untuk kegiatan okulasi tidak baik. Kegiatan okulasi yang dilakukan bersifat borongan, sehingga banyak okulator memanen entres secara sembarangan yang mengakibatkan ketidakcocokan antara mata entres yang ditempelkan dengan batang bawah. Selain itu, pengawasan mandor terhadap karyawan saat proses pemanenan entres sangat kurang. Menurut Boerhendry dan Amypalupy (2010), perbedaan tingkat keberhasilan okulasi disebabkan oleh kompatibel atau kecocokan antara batang atas dan batang bawah saat dilakukan okulasi. Oleh sebab itu perlu diperhatikan kompatibel antar umur entres dan batang bawah serta jenis okulasi yang dilakukan pada kegiatan tersebut. 


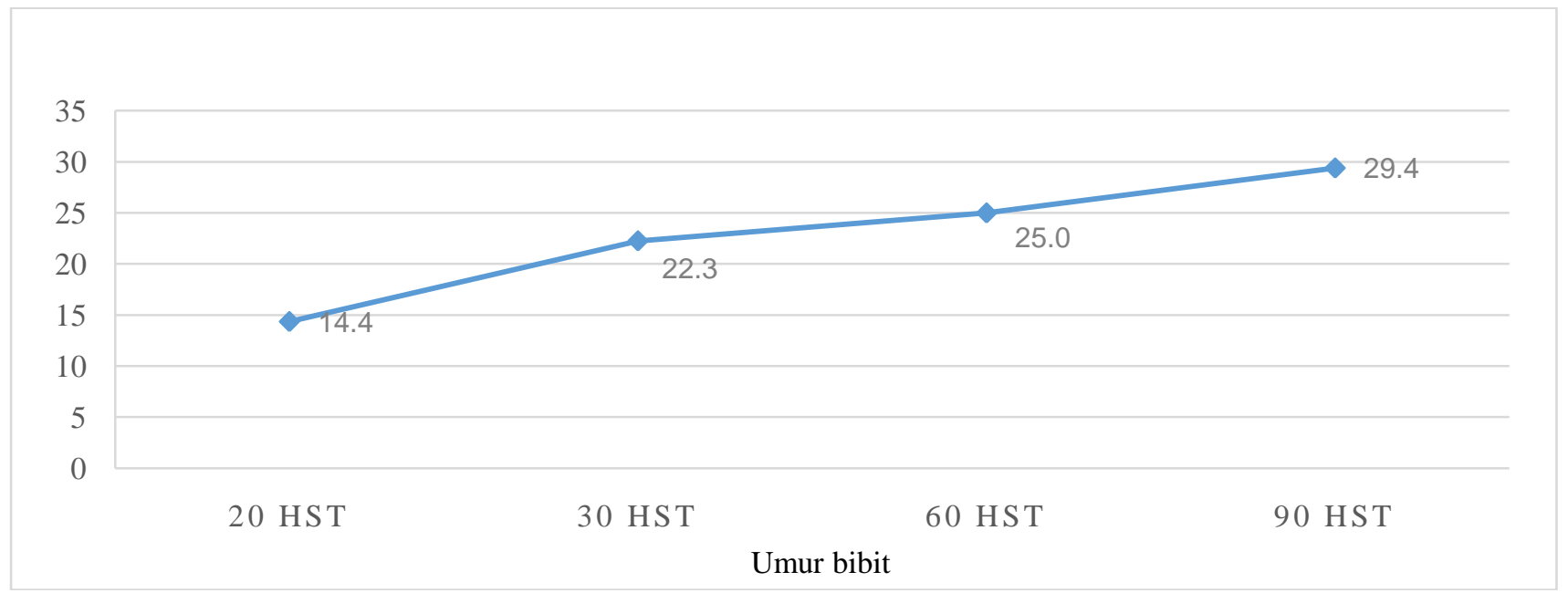

Gambar 2. Rata-rata pertumbuhan tinggi bibit karet dalam polybag klon PB 260 pada berbagai variasi umur

Berdasarkan hasil (Gambar 2) pengamatan, rata-rata pertumbuhan tinggi tunas mengalami peningkatan yang signifikan setiap bulannya. Pertumbuhan tunas ini dipengaruhi oleh faktor genetik dan faktor lingkungan. Goncalves et al (2006) menyatakan bahwa kecepatan tinggi tanaman dipengaruhi oleh faktor genetik misalnya fitohormon yang berkorelasi dengan lingkungan. Pada grafik 1, terlihat bahwa pertumbuhan bibit karet mengalami peningkatan yang sangat signifikan saat berumur 20 hari setelah tanam (HST) hingga 30 HST. Penurunan kecepatan pertumbuhan tinggi tunas pada bibit saat memasuki umur 60 - 90 hst. Penurunan kecepatan pertumbuhan tinggi tunas ini terjadi karena adanya pembentukan payung satu. Menurut Marchino et al (2010), pertambahan tinggi tunas suatu saat akan terhambat atau terhenti sementara diakibatkan oleh pertumbuhan payung satu setelah payung terbentuk sempurna pertumbuhan tinggi akan kembali tumbuh dengan cepat untuk pertumbuhan payung berikutnya. Tinggi rendahnya payung pertama pada bibit karet akan mempengaruhi tinggi rendahnya perkembangan tunas kedua dan secara tidak langsung mempengaruhi persiapan karet untuk disadap saat memasuki masa tanaman menghasilkan (TM).

\section{Diameter Bibit Okulasi}

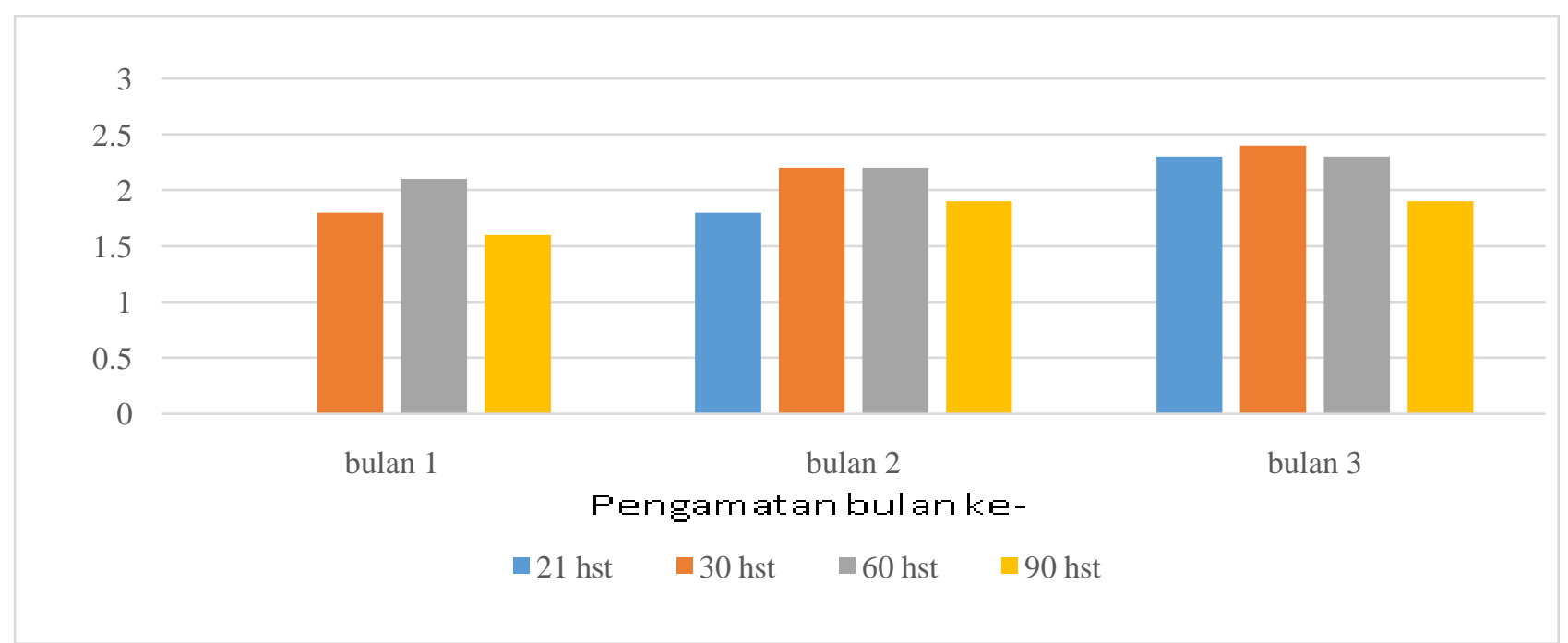


Pertumbuhan diameter pada bibit polybag karet klon PB 260 dengan berbagai variasi umur dapat dilihat pada Gambar 3. Berdasarkan hasil pengamatan pada grafik dua, pertumbuhan diameter bibit karet setiap bulannya mengalami peningkatan. Pertumbuhan diameter bibit dipengaruhi oleh suplay hara dan nutrisi yang dapat diambil oleh batang bawah atau scion. Salisbury dan Ross (1995), pertumbuhan diameter batang terjadi akibat pembelahan dan perkembangan sel kambium pembuluh yang sangat dipengaruhi oleh suplay hara dari media tanam, sehingga jika pasokan sumber hara terhambat akan menjadi faktor penghambat pertumbuhan tanaman. Hal ini terlihat pada bibit polybag yang berumur 90 hari memiliki diameter batang yang lebih kecil dibandingkan dengan umur bibit lainnya. Kemungkinan disebabkan oleh kurangnya suplay hara yang bisa diambil oleh batang bawah serta dipengaruhi juga oleh faktor lingkungan seperti iklim, curah hujan, dan suhu.

\section{Jumlah Payung}

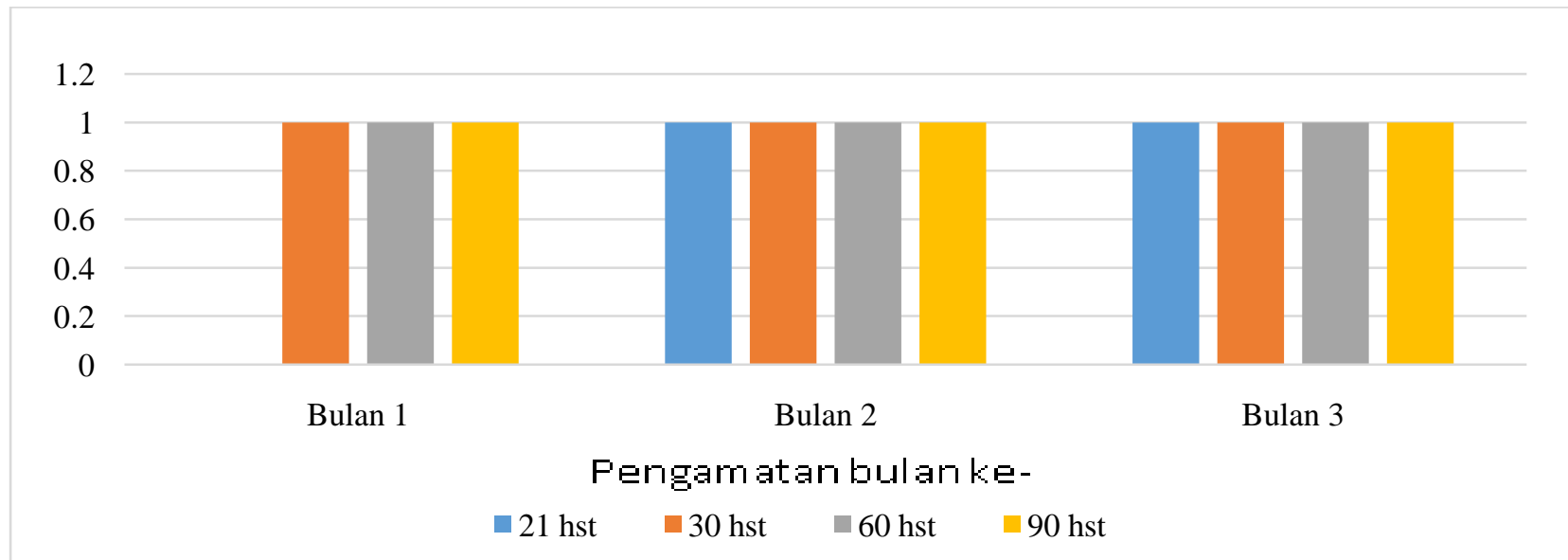

Gambar 4. Pertambahan pertumbuhan bibit karet dalam polybag klon PB 260 dengan berbagai variasi umur

Berdasarkan hasil pengamatan (Gambar 4) yang dilakukan selama tiga bulan, jumlah payung yang tumbuh selama pengamatan adalah satu tingkatan payung. Pembentukan payung karet pertama membutuhkan waktu 60 hari untuk tumbuh dengan sempurna. Payung atau mahkota karet adalah serangkaian daun karet atau daun yang keluar secara berkelompok yang bentuknya seperti payung. Menurut Setyamidjaja (1995), bibit karet dalam polybag sudah membentuk payung dua saat berumur lima bulan. Pernyataan ini tidak sesuai dengan pengamatan yang dilakukan, terlihat pada bibit karet umur 90 hari yang memasuki umur lima bulan tidak membentuk payung kedua pada pengamatan bulan ketiga.

Lakitan (1995), menyatakan bahwa laju fotosintat dapat mempengaruhi pertumbuhan batang. Pertumbuhan tanaman semakin lama akan semakin berkurang jika laju fotosintesis berkurang. Hal ini disebabkan oleh kurangnya unsur hara dan air karena okulasi yang tidak bersatu dengan baik. Selai itu, Menurut Marchino, Zhen, dan Suliansyah (2010), kondisi lingkungan yang tidak mendukung dapat menyebabkan pertumbuhan daun yang tidak optimal sehingga mengganggu proses fotosintesis. Hal ini mengakibatkan tanaman akan kekurangan energi untuk pertumbuhan payung berikutnya. Tidak terbentuknya payung kedua pada bibit karet dalam polybag yang berumur 90 hari, disebabkan oleh kompatibel antara batang atas dan batang bawah yang kurang baik serta adanya faktor lingkungan yang tidak mendukung pertumbuhan bibit karet tersebut. 
Sumber Batang Atas Entres (Scion), Batang Bawah (Rootstock), dan Sertifikasi Benih

Klon karet pada kebun batang entres yang ada di Balai ini pada awalnya berasal dari Balai Penelitian Sungei Putih di Medan, Sumatera Utara serta Pusat-Pusat Penelitian karet lainnya. Pengembangan terus dilakukan, sehingga saat ini batang atas langsung berasal dari Balai Penelitian Sembawa dengan luas 20.8 ha yang terdiri dari kebun komersial dan kebun koleksi. Batang bawah (rootstock) berasal dari benih (seedling) yang langsung di tanam di lapangan setelah dilakukan pendederan atau penyemaian terlebih dahulu. Luas lahan untuk batang bawah ini tidak menentu karena tidak memiliki lahan yang tetap. Penenaman batang bawah dilakukan di gawangan TBM karet yang berumur 1-3 tahun, sehingga penanaman batang bawah selanjutnya harus menunggu peremajaan karet tua.

Benih batang bawah diperoleh dari Balai Penelitian Sungai Putih dan Perusahaan swasta. Hal ini disebabkan masa panen benih atau pecah biji di Balai Penelitian ini terjadi pada bulan Februari sedangkan penanaman dilakukan pada bulan September yang merupakan awal musim hujan. Sifat benih karet yang rekalsitran mengakibatkan benih karet tidak bisa bertahan lama dalam penyimpanan karena kadar air benih dan kualitasnya semakin berkurang. Oleh sebab itu, benih untuk batang bawah didapatkan dari Balai Penelitian Sungai Putih dan perusahaan-perusahaan yang masa panen biji karet pada bulan JuliSeptember. Balit Sungai Putih mengirimkan benih karet dengan setiap kali pengirimannya sebanyak 5000 biji yang digunakan UBT untuk ditanam di lapangan sebagai batang bawah. Klon yang digunakan untuk entres maupun batang bawah merupakan klon-klon anjuran yang memiliki kualitas yang unggul. Klon yang digunakan untuk batang bawah merupakan klon campuran. klon entres yaitu jenis PB, IRR, BPM, RRIC, PR, RRIM, GT, AVROS, PPN, BN, DS, TR, dan IHP.

Sertifikasi bibit (Gambar 5) karet di Balai Penelitian Sembawa dilakukan oleh Badan Sertifikasi dan Tanaman Perkebunan. Sertifikasi ini dilakukan agar mutu bibit yang diperjualbelikan di Balai Penelitian ini memiliki kualitas yang sangat baik. Bibit karet yang dinyatakan sebagai bibit yang baik memiliki kriteria-kriteria tertentu. Bibit Stump Mata Tidur (SMT) karet memiliki kriteria panjang akar yang lurus $30 \mathrm{~cm}$, pangkal akar hingga mata tunas berukuran $10 \mathrm{~cm}$, dan dari mata tunas hingga ujung $5-7 \mathrm{~cm}$.

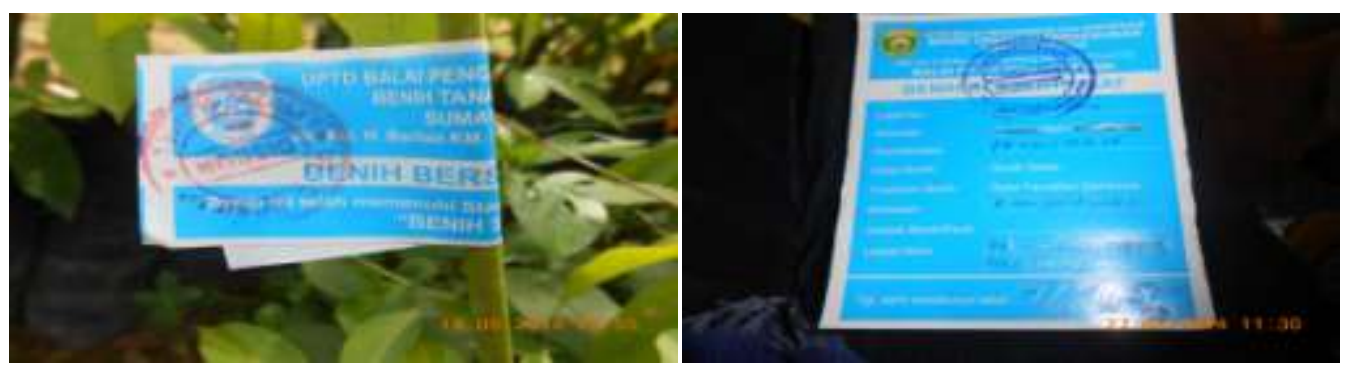

Gambar 5. Bibit yang memiliki sertifikasi oleh Badan Sertifikasi Tanaman Perkebunan

\section{Pemasaran Bibit Karet}

Konsumen yang melakukan pembelian di Balai Penelitian ini yaitu petani, pemerintah, maupun perusahaan-perusahaan swasta. Bibit yang diperjual belikan dapat berupa benih, bibit stump mata tidur (SMT) dan bibit dalam polybag. Harga yang diberlakuakan untuk setiap jenisnya berbeda- beda. Harga benih karet Rp 80, harga SMT karet karet $\mathrm{Rp}$ 6500, dan harga bibit karet dalam polybag $\mathrm{Rp} 9000$. Konsumen yang melakukan pembelian dapat melakukannya langsung di kantor bagian Urusan Bahan Tanam (UBT) atau kantor pemasaran Balai Penelitian Sembawa. Data jumlah ketersediaan dan pembelian bibit SMT dapat dilihat pada Tabel 7. 
Bul. Agrohorti 3 (2) : 252 - 262 (2015)

Tabel 7. Data pembelian stump mata tidur (SMT) karet tahun 2011 - 2013

\begin{tabular}{lrr}
\hline Tahun & \multicolumn{1}{c}{ SMT } & Pembelian \\
\cline { 2 - 3 } & \multicolumn{1}{c}{ Ketersediaan } \\
\cline { 2 - 3 } 2011 & 769179 & 481127 \\
2012 & 1326136 & 537335 \\
2013 & 1576373 & 1142945 \\
\hline Jumlah & 3671688 & 2161407 \\
\hline Sumber : Laporan produksi dan pembelian bibit SMT tahu 2011 - 2013 & &
\end{tabular}

Peningkatan permintaan konsumen terlihat dari tahun ke tahun terutama permintaan terhadap SMT karet. Permintaan ini berasal dari perusahaanperusahaan swata yang membeli bibit dalam jumlah yang sangat besar. Jenis klon karet yang memiliki tingkat permintaan yang paling tinggi adalah $\mathrm{PB}$ 260 baik dalam bentuk SMT maupun bibit polybag dibandingkan dengan klon karet jenis lainnya. Permintaan bibit SMT karet tahun 2014 mencapai 8 000000 SMT untuk pemenuhan permintaan tersebut telah disediakan lebih kurang 5000 bibit dan bibit SMT yang masih tersedia pada pada tahun 2013. Keterbatasan lahan batang bawah yang dimiliki sehingga untuk pemenuhan permintaan bibit dilakukan secara bertahap.

Bibit dengan jenis polybag dapat langsung dilakukan bila klon dan jumlah yang ingin dibeli konsumen sesuai. Bila tidak pembelian dapat dilakukan secara bertahap. Proses pembelian bibit karet dengan jenis SMT dilakukan dengan kontrak pembelian yang telah disepakati oleh konsumen dan pihak UBT. Biasanya untuk pembelian SMT dalam jumlah banyak memiliki kontrak lebih kurang lima tahun atau lebih. Hal ini disesuaikan oleh kemampuan bagian UBT untuk memenuhi atau menolak permintaan bibit dari konsumen dalam pembelian SMT. Penggunaan bibit yang dibeli konsumen biasanya untuk kebutuhan pribadi atau penanaman karet dilahan baru yang akan ditanami lahan karet oleh perusahaan besar maupun petani di berbagai wilayah Indonesia seperti Jambi, Bangka Belitung, Lampung, Kalimantan, Sulawesi, dan lain-lain.

Transportasi
Bibit yang telah diseleksi dengan kriteria yang telah ditentukan dikemas dalam kotak kayu yang berukaran $50 \mathrm{~cm}$ x $50 \mathrm{~cm}$ x $50 \mathrm{~cm}$ yang dalam satu kotaknya terdapat 204 SMT. Sebelumnya kotak tersebut diisi dengan serbuk gergaji yang disiram dengan air dengan tujuan menjaga kelembaban SMT selama perjalanan. Kotak kayu tersebut ditutup menggunakan papan kayu yang dipaku dan tali plastizer serta dijepit dengan aluminum untuk menguatkan ikatan. Pembayaran dilakukan dengan cara tunai dan konsumen membayar uang muka 30 $\%$ dari bibit yang dibelinya. Alat transportasi yang digunakan untuk transportasi bibit tidak langsung disediakan oleh Balai Penelitian Sembawa tetapi disiapkan sendiri oleh konsumen.

\section{KESIMPULAN}

Manajemen pembibitan sangat dipengaruhi oleh kualitas dan kuantitas para karyawan mulai dari manajer hingga mandor mampu merencanakan dan mempunyai strategi dalam mencapai tujuan bersama. Keberhasilan okulasi yang masih rendah yaitu $72 \%$, dipengaruhi oleh kurangnya pengawasan mandor dalam pemanenan batang atas oleh karyawan, jauhnya lokasi batang bawah yang diokulasi membuat kualitas batang atas menurun. Pertumbuhan bibit polybag dipengaruhi oleh suplay hara yang dipasok oleh batang bawah dan faktor lingkungan. Sertifikasi bibit karet dilakukan oleh Badan Pengawasan dan Perkebunan dengan kriteriakriteria bibit yang telah ditentukan. Transportasi bibit disediakan langsung oleh konsumen.

\section{DAFTAR PUSTAKA}

[BI] Bank Indonesia. 2007. Sistem Informasi Pola Pembiayaan/Lending Model Usaha Kecil [internet]. [diunduh 2013 Maret 16] 
Bul. Agrohorti 3 (2) : $252-262$ (2015)

tersedia pada (http:/www.bi.go.id./sipuk/lm/ind/karet).

Boerhendry, I., Amypalupi, K. 2010. Optimalisasi produktivitas karet melalui penggunaan bahan tanam, Pemeliharaan, Sistem Eksploitasi dan Peremajaan Tanaman. J. Litbang Pert. 30(2) : 23-30.

Chatib, H.S.P. 2012. Budidaya Tanaman Karet. Palembang (ID). Dinas Perkebunan Provinsi Sumatera Selatan.

Dinas Perkebunan Provinsi Sumatera Utara. Kebijakan Pembinaan Penangkaran Benih Tanaman Perkebunan. Makalah yang disampaikan dalam kegiatan pembinaan dan inventarisasi penangkar benih tanaman perkebunan dinas Provinsi Sumatera Utara. 28-29 Juni 2012.

Goncalves, Silva, dan Scalovi. 2006. Genetic Variability for Grith Grow and Rubber
Yield in Hevea Brassiliensis. Agriculture science. 63(3): 246-254

Haryanto, B. 2012. Budidaya Karet Unggul. Cetakan pertama. Yogyakarta (ID): Pustaka Baru Press. 240 hlm.

Lakitan, B. 1996. Holtikultura: Teori, Budidaya, dan Pasca Panen. Rajawali. Jakarta (ID): CV. Yasaguna. $75 \mathrm{hlm}$

Marchino, F., Suliansyah, I., Zen, M.F. 2010. Pertumbuhan Stump Mata Tidur Klon Entres Tanaman Karet (Hevea brassiliensis Muel Arg) Pada Batang Bawah PB 260 Di lapangan. Jerami. 2010; 3(3): 7-14.

Salisbury, F.B. dan Ross C W. 1995. Plant Physiology. D R Lukman, Ir Sumaryono. Penerjemah. Bandung (ID). 344 hlm.

Setyamidjaja, D. 1995. Karet, Budidaya dan Pengolahan. Yogyakarta (ID); Kanisius. 206 hlm 